Simultaneous and integrated neutron-based techniques for material analysis of a metallic ancient flute

This article has been downloaded from IOPscience. Please scroll down to see the full text article.

2013 Meas. Sci. Technol. 24095601

(http://iopscience.iop.org/0957-0233/24/9/095601)

View the table of contents for this issue, or go to the journal homepage for more

Download details:

IP Address: 151.24.93.103

The article was downloaded on 29/07/2013 at 07:43

Please note that terms and conditions apply. 


\title{
Simultaneous and integrated neutron-based techniques for material analysis of a metallic ancient flute
}

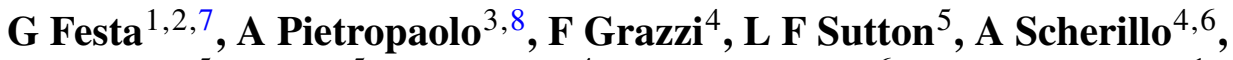 \\ L Bognetti $^{5}$, A Bini ${ }^{5}$, E Barzagli $^{4}$, E Schooneveld $^{6}$ and C Andreani $^{1}$ \\ ${ }^{1}$ Università degli Studi di Roma 'Tor Vergata' and Centro NAST, Via della Ricerca Scientifica 1, \\ I-00133 Rome, Italy \\ ${ }^{2}$ Università degli Studi di Milano-Bicocca, Piazza della Scienza 3, I-20126 Milan, Italy \\ ${ }^{3}$ Consiglio Nazionale delle Ricerche Istituto di Fisica del Plasma 'P Caldirola', Via R Cozzi 53, I-20125 \\ Milano, Italy \\ ${ }^{4}$ CNR-ISC, Firenze, Italy \\ ${ }^{5}$ Accademia Nazionale di S Cecilia, Rome, Italy \\ ${ }^{6}$ STFC-ISIS Facility, Chilton, Didcot OX11 ORA, UK \\ E-mail: giulia.festa@roma2.infn.it
}

Received 15 March 2013, in final form 20 June 2013

Published 26 July 2013

Online at stacks.iop.org/MST/24/095601

\begin{abstract}
A metallic 19th century flute was studied by means of integrated and simultaneous neutron-based techniques: neutron diffraction, neutron radiative capture analysis and neutron radiography. This experiment follows benchmark measurements devoted to assessing the effectiveness of a multitask beamline concept for neutron-based investigation on materials. The aim of this study is to show the potential application of the approach using multiple and integrated neutron-based techniques for musical instruments. Such samples, in the broad scenario of cultural heritage, represent an exciting research field. They may represent an interesting link between different disciplines such as nuclear physics, metallurgy and acoustics.
\end{abstract}

Keywords: neutron diffraction, neutron radiative capture, neutron radiography, musical instrument, acoustics

(Some figures may appear in colour only in the online journal)

\section{Introduction}

Neutrons represent a powerful tool to investigate the microscopic structure of materials in a non-destructive manner. Neutron diffraction (ND) $[1,2]$ results determine the phase composition and microstructural properties of materials, neutron resonance capture analysis (NRCA) [3, 4] provides the elemental composition and neutron radiography (NR)

\footnotetext{
${ }^{7}$ Author to whom any correspondence should be addressed.

8 Present address: ENEA-Cenro Ricerche Frascati, Via E Fermi 45, 00044 Frascati, Rome, Italy.
}

and neutron tomography (NT) $[5,6]$ recognize internal features of the samples. All these techniques have shown their potential in the investigation of complex artifacts of cultural and artistic relevance (see for instance [7-12]). In this paper a novel approach is proposed to investigate the complex structure and composition of a metallic musical instrument, a metallic flute from the Accademia Nazionale di Santa Cecilia Musical Instruments Collection (Rome, Italy), by means of the integrated and simultaneous use of ND, NRCA and NR on a single neutron beamline, namely the INES neutron diffractometer [13, 14] at the ISIS facility (Rutherford Appleton Laboratory, UK). These 
investigations were complemented and correlated to the acoustic performance of the flute by a classical spectral analysis of the emitted sound.

\subsection{Motivation}

The INES diffractometer was purposely built as a time-offlight (TOF) neutron diffractometer (a general description of a neutron diffractometer and the TOF technique can be found in [15]), equipped with squashed, 20 bar ${ }^{3} \mathrm{He}$ detectors distributed on the horizontal plane, spanning an angle between $12^{\circ}$ and $171^{\circ}$, corresponding to an accessible $d$-spacing of 0.1 to $16 \AA$. The INES beamline is characterized by a high degree of flexibility, offering a maximum beam size at the sample position of $3.0 \times 3.0 \mathrm{~cm}^{2}$; it has a generous $(80 \mathrm{~cm}$ diameter $\times 80 \mathrm{~cm}$ height $)$ vacuum tank and a relatively wide space around the tank for the installation of further instrumentation. The under-moderated neutron beam available (room temperature water moderator) at INES also makes available a relatively large number of neutrons (about $10^{6} \mathrm{n} \mathrm{s}^{-1} \mathrm{~cm}^{-2}$ ) in the epithermal energy range, where most absorption resonances are found for a large number of materials. The overall energy spectrum features a maxwellian peak at about $30 \mathrm{meV}$ (thermal component) and a tail in the range $1 \mathrm{eV}<E<1 \mathrm{MeV}$ (epithermal/fast component). The reader is referred to $[16,17]$ for a thorough discussion. This suggested the idea of integrating the standard ND capabilities of INES with other techniques. After the preliminary measurements with $\mathrm{ND}$ and neutron resonance transmission (NRT) a permanent installation for both NRCA [18] and NR [19] was provided. One of the main advantages of this approach is the reduced neutron activation induced in the examined sample: neutron techniques are known for inducing a moderate residual activity in some metals (for instance $\mathrm{Cu}, \mathrm{Ag}, \mathrm{Au}$ ). However, in the case described in this paper, since measurements were simultaneous the irradiation time was reduced to a minimum (a few hours), with a drastic reduction in the induced activity. An image of the investigated artifact, a small metallic duct flute from Accademia Nazionale di Santa Cecilia, is shown in figure 1. The flute, built by 19th century French flute maker Charles Mathieu, is a vertical metal flute in D with six finger-holes on the front. The body of the instrument is made of a laminated sheet of metal, curved and soldered on the back all along the pipe, while the mouthpiece appears to be made through a casting process. The object was also restored by the Accademia around the year 1992 for preservation and exhibition purposes.

\section{Experiment}

The flute was characterized by means of simultaneous and integrated use of ND, NRCA and NR as follows. The sample was analyzed in four different zones. The irradiated areas and corresponding neutron radiographies are reported in figure 1. Areas A, B and C were studied by ND, NRCA and NR while zone $\mathrm{D}$ was studied by NR only due to the limited beam-time available for the experiment. A detailed description of all these methods is beyond the scope of this paper; here we only recall

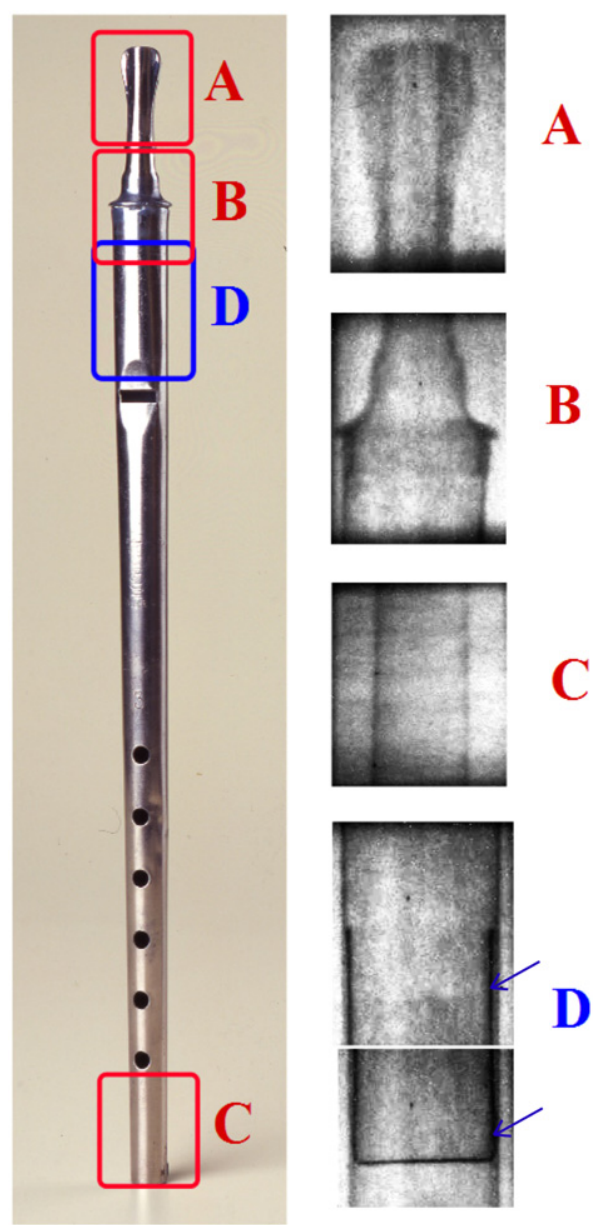

Figure 1. Flute studied via neutron diffraction, neutron resonance capture analysis and neutron radiography. Areas irradiated by neutrons during the experiment: $\mathrm{A}=$ mouthpiece, $\mathrm{B}=$ welded region and $\mathrm{C}=$ body; the area $\mathrm{D}=$ fipple plug was detected via neutron radiography. The fipple plug (internal metallic plate) is indicated by arrows. Radiographic images of the irradiated areas are also reported. Flute dimensions: height $=35 \mathrm{~cm}$, max diameter $=$ $2 \mathrm{~cm}$.

some of their characteristics, useful for the comprehension of results.

ND is a powerful technique that makes use of thermal neutrons $\left(E_{n} \approx 25 \mathrm{meV}\right)$ for investigating the crystal structure of materials [20, 21]. The diffraction process is described as the reflection of the incident beam by crystal planes $(h k l)$. The well known Bragg's law $n \lambda=2 d_{h k l} \sin \theta$ in the case of TOF measurements can be rewritten as a relation between the TOF of neutrons scattered from a set of planes in the sample and the spacing between these planes, $d_{h k l}$ :

$$
(\mathrm{TOF})_{h k l}=\frac{2 m_{n}}{h} L d_{h k l} \sin \theta_{0}
$$

where $\theta_{0}$ is a fixed scattering angle of a specific detector. The use of more detectors provides a full diffraction pattern delivered by any of them with a different $d$-spacing range and resolution according to their position with respect to the primary neutron beam and the sample. Diffraction patterns showing Bragg peaks, obtained from a measurement, could be used all together to identify phases or structures, or to derive texture information. The experimental signal from a 


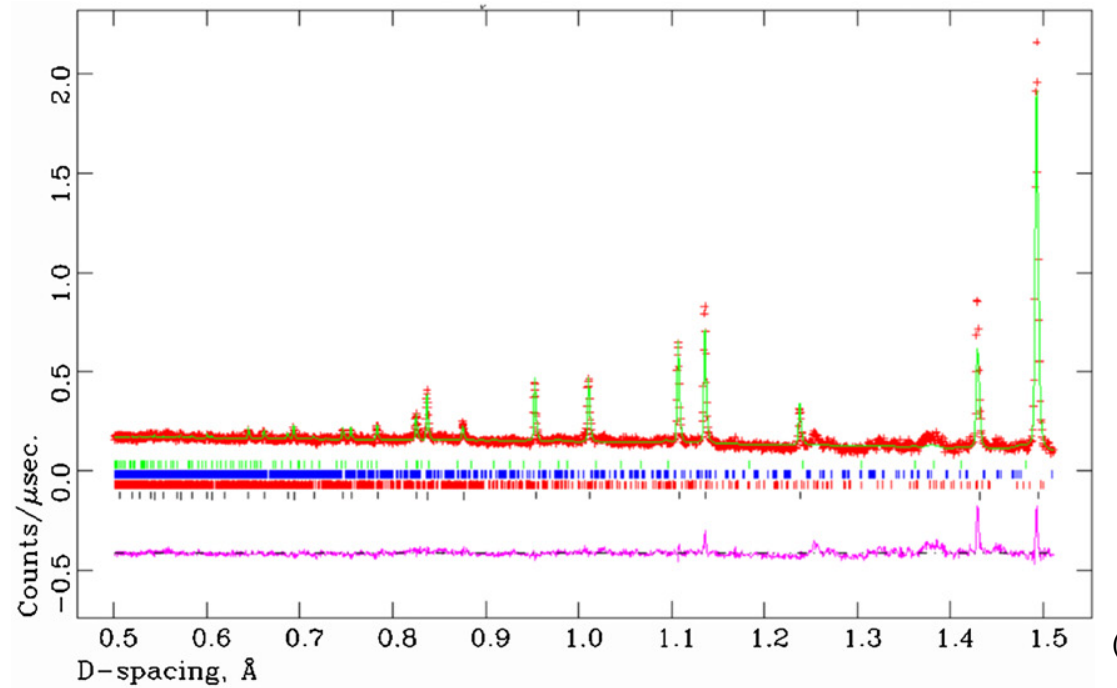

(a)
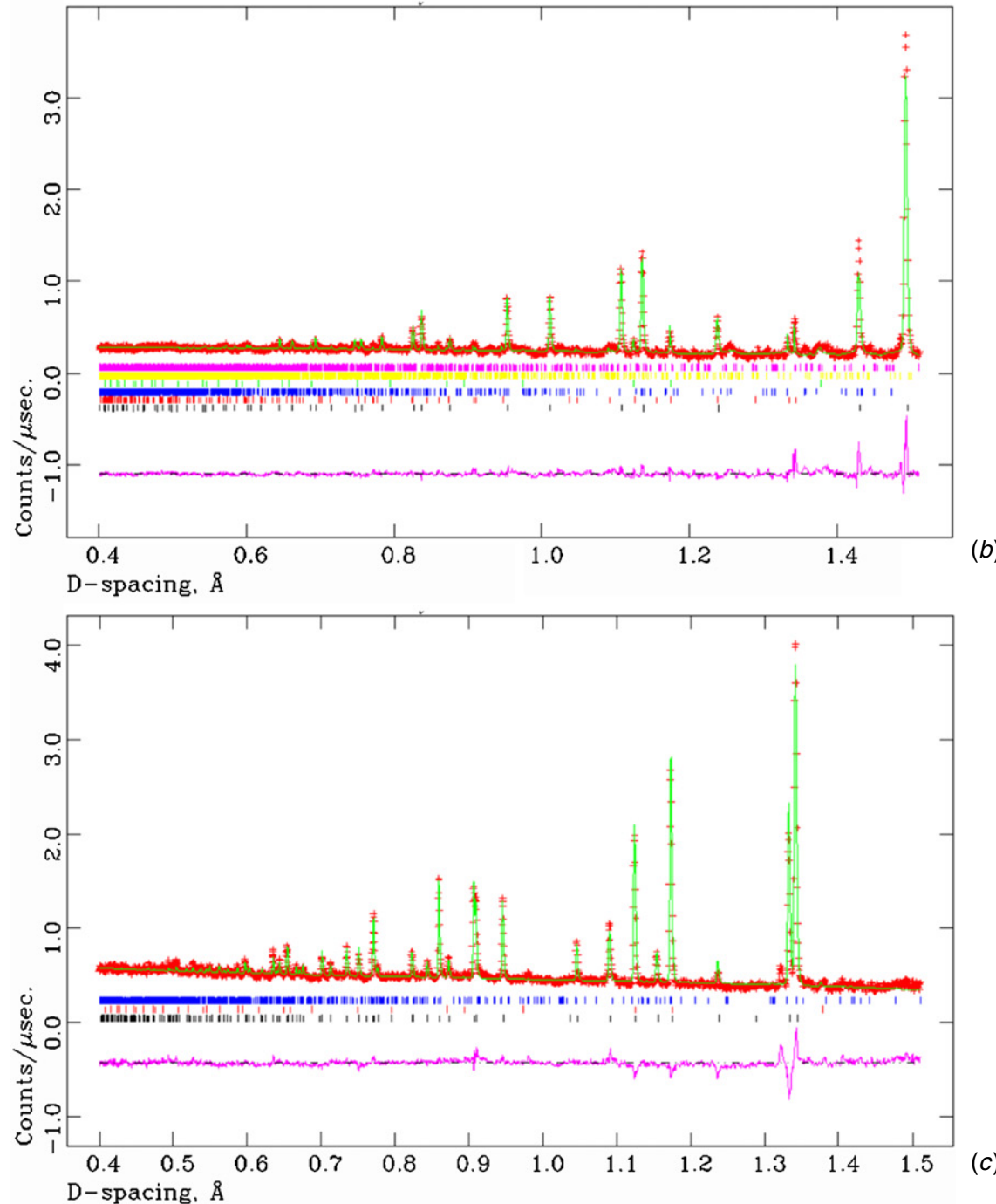

Figure 2. Diffraction spectra of the flute are reported (normalized number of counts as a function of $d$-spacing). Best fit of data is also shown, with the peak position of the different components, and residue is reported in violet. (a) Mouthpiece area (A in figure 1) with peaks labeled as lead $=$ black, tin (II) sulphate $=$ red, lead tetroxide $=$ blue, zincite $=$ green; $(b)$ welded region $(\mathrm{B}$ in figure 1$)$ with peaks labelled as lead $=$ black, zinc $=$ red, herzenbergite $=$ blue, palladium $=$ green, tin (II) sulphate $=$ yellow, lead tetroxide $=$ red; $(c)$ body region $(\mathrm{C}$ in figure 1) with peaks labelled as zinc $=$ black, palladium $=$ red and herzenbergite $=$ blue. 


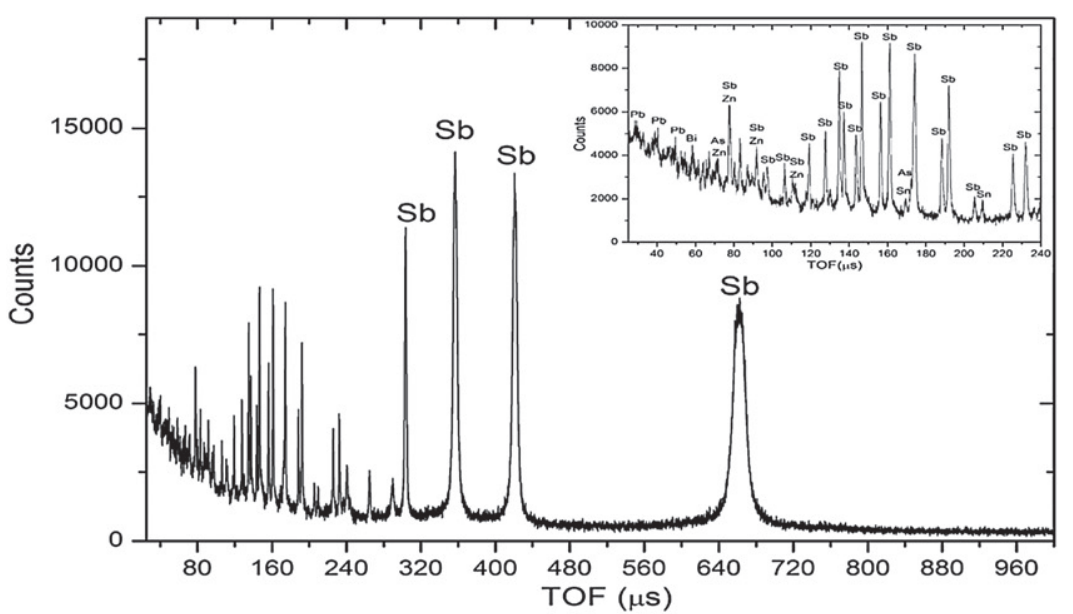

(a)
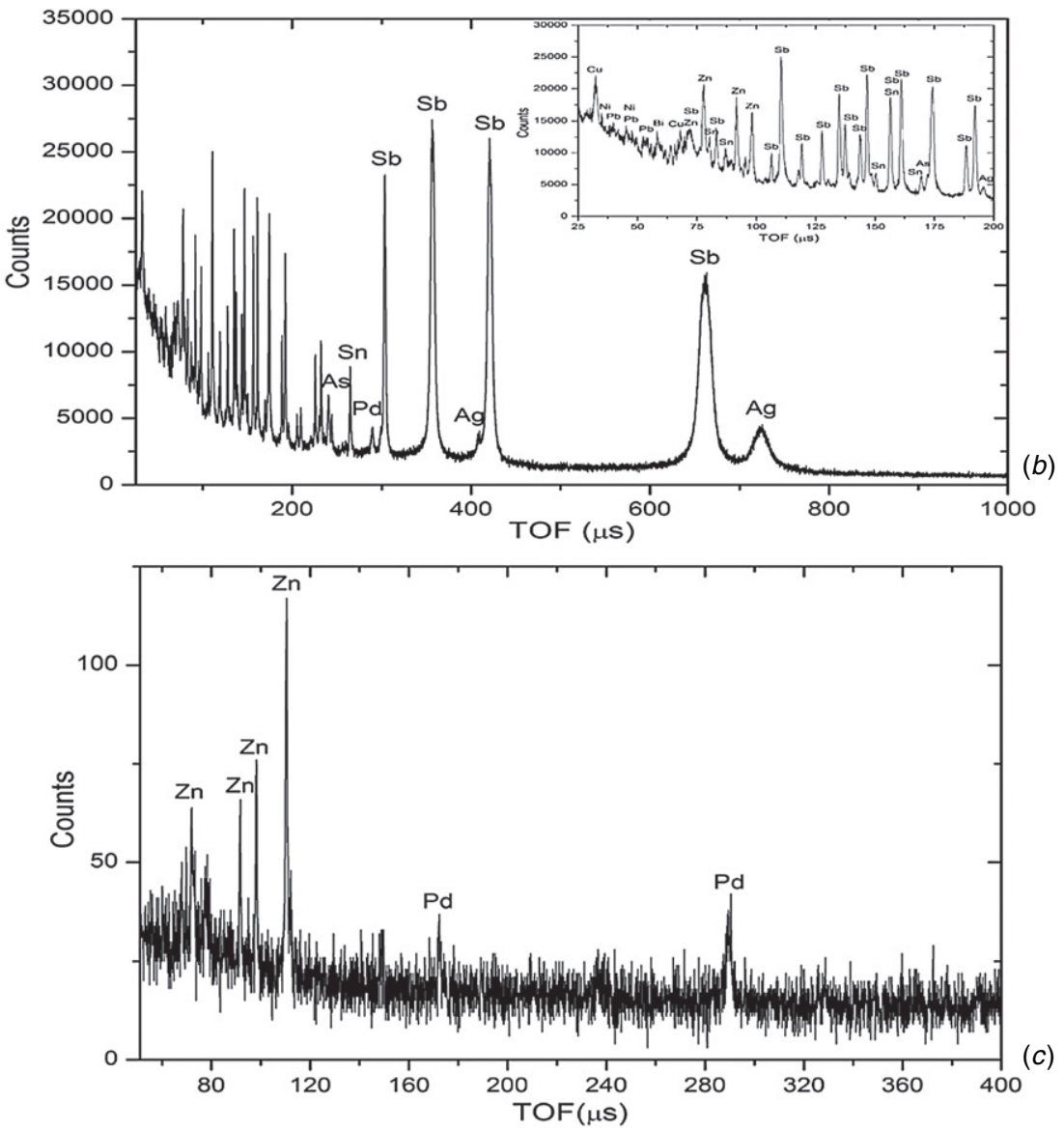

Figure 3. Neutron resonance capture analysis results of the three sections of the flute: $(a)$ mouthpiece (A in figure 1); $(b)$ welded region (B in figure 1); (c) body area (C in figure 1). Detected peaks are labeled.

diffraction measurement taken on polycrystalline samples is a pattern of Bragg peaks, whose positions are directly related to the crystal lattice reflections and are used to identify phases and structures. The wavelength position of the Bragg peaks can be readily reconstructed with the TOF technique [22].

The NRCA technique [3, 4] uses epithermal neutrons $\left(E_{n}\right.$ from $1 \mathrm{eV}$ up to $1 \mathrm{keV}$ ) to investigate the elemental composition of the irradiated sample. Neutrons impinging onto materials are captured by the nuclei. For many nuclear species, especially metals, there are intense peaks in the absorption cross section called resonances. An absorbed neutron induces the transition of the nucleus to an excited state; its deexcitation to the ground state produces prompt gamma photons in a cascade. Eventually, gammas are detected by a standard photon detector (in this case, a crystal scintillator of yttrium-aluminum-perovskite (YAP) [23], coupled to a photomultiplier tube, placed on top of the sample tank). The value of the resonance energies $E_{r}$ was calculated from the TOF position of the peaks using the relation $E_{r}=m_{n} \frac{L_{0}^{2}}{2(\mathrm{TOF})^{2}}$ where $m_{n}$ is the neutron mass and $L_{0}$ the neutron flight path.

The sample composition could be determined, since the energies of the resonances are characteristic of each isotope. 
Table 1. Main peaks of the NRCA spectrum. The value of the resonance energies $E_{r}$ was calculated from the TOF position of the peaks using $E_{r}=m_{n} \frac{L_{0}^{2}}{2(\mathrm{TOF})^{2}}$, where $m_{n}$ is the neutron mass, $L_{0}$ the neutron flight path and TOF is the time of flight.

\begin{tabular}{|c|c|c|c|}
\hline Element & $\begin{array}{l}\text { Soldering TOF } \\
(\mu \mathrm{s}) ; E_{r}(\mathrm{eV})\end{array}$ & $\begin{array}{l}\text { Mouthpiece TOF } \\
(\mu \mathrm{s}) ; E_{r}(\mathrm{eV})\end{array}$ & $\begin{array}{l}\text { Body TOF } \\
(\mu \mathrm{s}) ; E_{r}(\mathrm{eV})\end{array}$ \\
\hline $\mathrm{Ag}$ & $724.0 ; 5.2$ & - & - \\
\hline $\mathrm{Sb}$ & $661.7 ; 6.2$ & $661.9 ; 6.2$ & - \\
\hline $\mathrm{Sb}$ & $420.7 ; 15.4$ & $420.8 ; 15.4$ & - \\
\hline $\mathrm{Ag}$ & $408.3 ; 16.3$ & - & - \\
\hline $\mathrm{Sb}$ & $356.8 ; 21.4$ & $356.6 ; 21.4$ & - \\
\hline $\mathrm{Sb}$ & $303.3 ; 29.5$ & $303.4 ; 29.6$ & - \\
\hline $\mathrm{Ag}$ & $299.0 ; 30.4$ & - & - \\
\hline $\mathrm{Pd}$ & $289.1 ; 32.5$ & - & $290.5 ; 32.1$ \\
\hline $\mathrm{Sn}$ & $264.8 ; 38.8$ & $264.8 ; 38.8$ & - \\
\hline $\mathrm{Sn}$ & $243.8 ; 45.7$ & - & - \\
\hline As & $240.3 ; 47.1$ & $240.6 ; 47.0$ & - \\
\hline $\mathrm{Sb}$ & $232.2 ; 50.4$ & $232.2 ; 50.40$ & - \\
\hline $\mathrm{Ag}$ & $230.0 ; 51.4$ & - & - \\
\hline $\mathrm{Sb}$ & $225.4 ; 53.5$ & $225.6 ; 53.4$ & - \\
\hline $\mathrm{Ag}$ & $220.8 ; 55.7$ & - & - \\
\hline $\mathrm{Sn}$ & $209.5 ; 61.9$ & $209.4 ; 62.0$ & - \\
\hline $\mathrm{Sb}$ & $205.4 ; 64.4$ & $205.5 ; 64.4$ & - \\
\hline $\mathrm{Ag}$ & $195.7 ; 71.0$ & - & - \\
\hline $\mathrm{Sb}$ & $192.1 ; 73.7$ & $192.1 ; 73.7$ & - \\
\hline $\mathrm{Sb}$ & $188.3 ; 76.7$ & $188.3 ; 76.7$ & - \\
\hline $\mathrm{Sb}$ & $174.2 ; 89.6$ & $174.2 ; 89.6$ & - \\
\hline As & $172.2 ; 91.7$ & $172.1 ; 91.8$ & $172.3 ; 91.3$ \\
\hline $\mathrm{Sn}$ & $169.5 ; 94.6$ & $169.4 ; 94.7$ & - \\
\hline $\mathrm{Sb}$ & $161.1 ; 104.7$ & $161.1 ; 104.7$ & - \\
\hline $\mathrm{Sn}$ & $156.4 ; 111.1$ & $156.4 ; 111.1$ & - \\
\hline Sn & $150.3 ; 120.3$ & - & - \\
\hline background & $148.4 ; 123.4$ & - & - \\
\hline $\mathrm{Sb}$ & $146.6 ; 126.5$ & $146.5 ; 126.6$ & - \\
\hline $\mathrm{Sb}$ & $143.7 ; 131.6$ & $143.6 ; 131.8$ & - \\
\hline Background & $139.2 ; 140.3$ & - & - \\
\hline $\mathrm{Sb}$ & $137.4 ; 144.0$ & $137.3 ; 144.2$ & - \\
\hline $\mathrm{Sb}$ & $134.9 ; 149.4$ & $134.9 ; 149.4$ & - \\
\hline $\mathrm{Sb}$ & $130.3 ; 160.1$ & - & - \\
\hline $\mathrm{Sb}$ & $127.7 ; 166.7$ & $127.7 ; 166.7$ & - \\
\hline $\mathrm{Sb}$ & $119.1 ; 191.6$ & $119.2 ; 191.3$ & - \\
\hline Sn & $117.7 ; 196.2$ & - & - \\
\hline $\mathrm{Zn}$ & $110.6 ; 222.2$ & $110.7 ; 221.8$ & $110.2 ; 223.2$ \\
\hline $\mathrm{Sb}$ & $106.4 ; 240.1$ & $106.4 ; 240.1$ & - \\
\hline $\mathrm{Zn}$ & $98.2 ; 281.9$ & - & $98.2 ; 281.1$ \\
\hline $\mathrm{Sb}$ & $97.6 ; 285.3$ & $97.4 ; 286.5$ & - \\
\hline $\mathrm{Sb}$ & $95.4 ; 298.7$ & $95.4 ; 298.7$ & - \\
\hline As & $92.1 ; 320.4$ & - & - \\
\hline $\mathrm{Zn}$ & $91.7 ; 323.2$ & $91.7 ; 323.2$ & $91.8 ; 321.6$ \\
\hline As & $91.4 ; 325.4$ & - & - \\
\hline $\mathrm{Sn}$ & $87.1 ; 358.3$ & $87.2 ; 357.5$ & - \\
\hline $\mathrm{Sb}$ & $83.1 ; 393.6$ & $83.3 ; 391.7$ & - \\
\hline $\mathrm{Sn}$ & $80.4 ; 420.5$ & $80.3 ; 421.5$ & - \\
\hline $\mathrm{Zn}$ & $78.0 ; 446.8$ & $77.9 ; 447.9$ & - \\
\hline $\mathrm{Sb}$ & $77.6 ; 451.4$ & $77.5 ; 452.5$ & - \\
\hline $\mathrm{Zn}$ & $72.8 ; 512.9$ & - & $72.9 ; 510.0$ \\
\hline As & $71.6 ; 530.2$ & $71.1 ; 537.7$ & - \\
\hline $\mathrm{Cu}$ & $68.0 ; 587.8$ & - & - \\
\hline $\mathrm{Sb}$ & $67.1 ; 603.7$ & $67.1 ; 603.7$ & - \\
\hline $\mathrm{Sb}$ & $65.7 ; 629.7$ & $65.7 ; 629.7$ & - \\
\hline $\mathrm{Sb}$ & $64.0 ; 663.6$ & $63.9 ; 665.7$ & - \\
\hline $\mathrm{Sb}$ & - & $61.6 ; 716.3$ & - \\
\hline $\mathrm{Bi}$ & $58.3 ; 799.7$ & $58.3 ; 799.7$ & - \\
\hline $\mathrm{Pb}$ & $53.7 ; 939.9$ & - & - \\
\hline $\mathrm{Pb}$ & $45.2 ; 1324.6$ & $45.5 ; 1309.3$ & - \\
\hline $\mathrm{Zn}$ & $41.8 ; 1555.7$ & - & - \\
\hline As & $40.0 ; 1698.8$ & - & - \\
\hline
\end{tabular}

Table 1. (Continued.)

\begin{tabular}{llll}
\hline Element & $\begin{array}{l}\text { Soldering TOF } \\
(\mu \mathrm{s}) ; E_{r}(\mathrm{eV})\end{array}$ & $\begin{array}{l}\text { Mouthpiece TOF } \\
(\mu \mathrm{s}) ; E_{r}(\mathrm{eV})\end{array}$ & $\begin{array}{l}\text { Body TOF } \\
(\mu \mathrm{s}) ; E_{r}(\mathrm{eV})\end{array}$ \\
\hline $\mathrm{Pb}$ & $39.9 ; 1702.5$ & $39.9 ; 1702.5$ & - \\
$\mathrm{Ni}$ & $34.8 ; 2244.5$ & - & - \\
$\mathrm{Cu}$ & $32.4 ; 2589.3$ & - & - \\
$\mathrm{Pb}$ & - & $29.4 ; 3135.8$ & - \\
\hline
\end{tabular}

NR [5, 6] is a non-invasive method of testing the internal structure of an object. When a thermal neutron beam passes through any heterogeneous sample, it is attenuated by the sample material. Absorption and scattering processes are the interactions that contribute to beam attenuation. In conventional radiography the attenuation of the incident beam by the sample can be described by an exponential function: $I(x, y)=I_{0}(x, y) \mathrm{e}^{-\iint_{\text {path }} \mu(x, y, z) \mathrm{d} z}$ where $I(x, y)$ and $I_{0}(x, y)$ are the intensities of transmitted and incident beams in a plane $(x, y)$ transverse to the propagation direction $z$. The linear attenuation coefficient $(\mu)$ indicates the fraction of the beam that is absorbed or scattered per unit thickness of the absorber.

In our case, radiographs are recorded by the neutron imaging device described in [19]. Along with the investigation of materials, performed by means of the above mentioned neutron-based techniques, a detailed analysis of the acoustic spectrum of the flute was performed at the Accademia di Santa Cecilia. This included a series of measurements on audio recordings of ascending scales played on the flute.

Typical ND and NRCA spectra measured at different positions of the flute (see figure 1) are shown in figures 2 and 3 . The diffraction data have been normalized to the number of counts (through the incident monitor) and have been divided by the vanadium rod diffraction measurements in order to account for the detectors' efficiency. NRCA data from areas $\mathrm{A}$ and $\mathrm{B}$ were collected through a scintillator detector with an active area of about $20 \mathrm{~cm}^{2}$ mounted about $50 \mathrm{~cm}$ from the sample position outside the aluminium tank. The spectrum of area $\mathrm{C}$ was collected by a small detector composed of a YAP surface area of $1 \mathrm{~cm}^{2}$ and a thickness of $0.6 \mathrm{~cm}$, optically coupled to a silicon photomultiplier (SiPM) from Hamamatsu $\left(1 \mathrm{~mm}^{2}\right.$ active area) mounted $30 \mathrm{~cm}$ from the sample position inside the tank. Geometry and size differences explain the lower statistics of spectrum $\mathrm{C}$ in figure 2 compared to the others.

\section{Results and discussion}

The main peaks of the NRCA spectra were identified and are reported in table 1. Experimental spectra were examined and peaks were labeled by means of a comparison with the resonance energies related to $(n, \gamma)$ processes provided by tables of neutron resonances [24]. Natural isotope abundance was used to determine the theoretical energy spectrum of the elements in the sample. A semi-quantitative analysis of NRCA data was performed to identify the elements and their relative atomic percentages $(A(\%))$, by considering the relative intensities of the peak maxima, $I_{P}$, in the TOF spectra in 


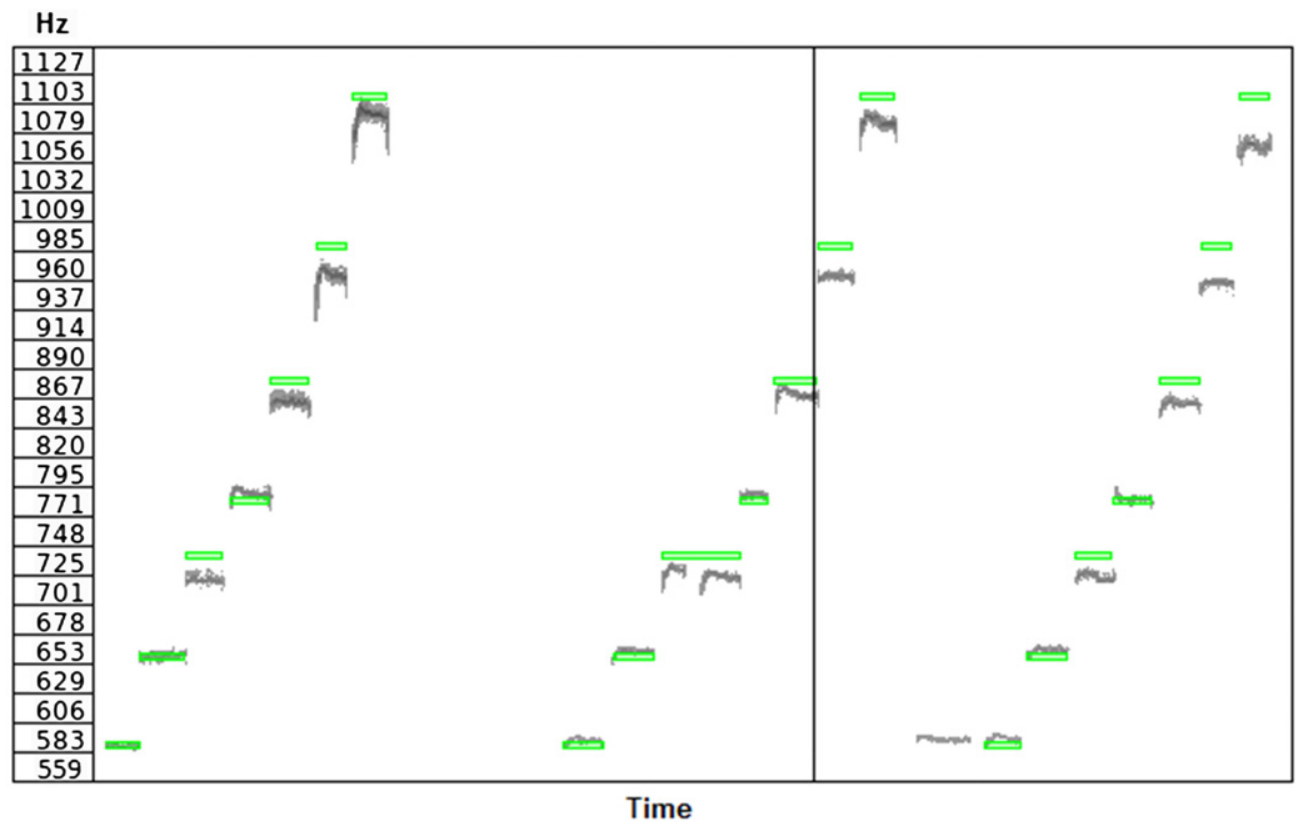

Figure 4. Section of the spectrogram. The green rectangles are the expected notes in the diatonic scale of D. The rectangles in the spectrogram (dark gray) are the actual pitches played. Spectrogram parameters: window shape: Hann window size 32768 with $75 \%$ overlap. Linear interpolation for $x$ and $y$ axes.

figure 3. The relative ratio of the detected elements was estimated using the relation [5]

$$
A=\frac{I_{P, 1} \sigma_{2} t_{2}^{2}}{I_{P, 2} \sigma_{1} t_{1}^{2}}
$$

where $\sigma_{1}$ and $\sigma_{2}$ are the radiative capture cross sections of natural elements at the resonance energy, while $t_{1}$ and $t_{2}$ are the time positions of the resonance peaks in the NRCA spectrum. While the object has a complex shape and selfabsorption effects are not mentioned in our calculation, a semi-quantitative 'degree of abundance' is reported in table 2. Diffraction data were analyzed using the standard phase analysis software GSAS [25] with the EXPGUI [26] interface, based on the Rietveld refinement method that provides weight fractions $\left(W_{t}(\%)\right)$ of the main phases present in the sample. Quantitative phase analysis is based on the principle that, in a multiphase sample, each phase exhibits a unique set of diffraction peaks. The measured diffraction spectra are thus the weighted sum of all single-phase patterns. Since the sample is made from a metal sheet, a careful check of the presence of texture (preferred orientation of crystal grains) has been performed by checking the relative intensity of pairs of $h \mathrm{kl}$ index diffraction peaks of the same phase in different detectors (and then at different scattering angles); no texture was found. Spectra of the three studied areas of the flute (A, B and C in figure 1) are shown in figure 2, together with the best fit obtained by the Rietveld analysis. Results are related to the average composition of the irradiated sample areas. It has to be considered that the neutron beam has a thermal component (used for ND) and an epithermal component (used for NRCA) and the collimation system, used during the measurements, effectively absorbs thermal neutrons. The consequence is that the area studied by NRCA is larger than the area under irradiation during ND.
Table 2. Results of neutron diffraction (ND) and neutron resonance capture analysis (NRCA) on the flute. In the table the weight percentage of the detected phase, $W_{t}(\%)$ from ND data, and detected elements from NRCA data are reported. A, B and C are the labels of irradiated areas reported in figure 1 .

\begin{tabular}{|c|c|c|c|c|}
\hline & \multicolumn{2}{|l|}{ ND } & \multicolumn{2}{|c|}{ NRCA } \\
\hline & Phase & $W_{t}(\%)$ & Element & Amount \\
\hline \multirow[t]{6}{*}{ A } & Lead $(\mathrm{Pb})$ & $90.1 \pm 0.3$ & Lead $(\mathrm{Pb})$ & Main \\
\hline & Lead tetroxide $\left(\mathrm{Pb}_{3} \mathrm{O}_{4}\right)$ & $5.8 \pm 0.3$ & Zinc (Zn) & Minor \\
\hline & Tin(II) sulphate $\left(\mathrm{SnSO}_{4}\right)$ & $2.2 \pm 0.1$ & Antimony (Sb) & Trace \\
\hline & Zincite $(\mathrm{ZnO})$ & $1.89 \pm 0.02$ & Arsenic (As) & Trace \\
\hline & & & Bismuth (Bi) & Trace \\
\hline & & & Tin $(\mathrm{Sn})$ & Trace \\
\hline \multirow{10}{*}{ B } & Lead $(\mathrm{Pb})$ & $77.1 \pm 0.2$ & Lead $(\mathrm{Pb})$ & Main \\
\hline & Tin(II) sulphate $\left(\mathrm{SnSO}_{4}\right)$ & $8.9 \pm 0.2$ & Zinc (Zn) & Major \\
\hline & Herzenbergite $(\mathrm{SnS})$ & $5.1 \pm 0.1$ & Copper $(\mathrm{Cu})$ & Major \\
\hline & $\operatorname{Zinc}(\mathrm{Zn})$ & $5.06 \pm 0.03$ & Nickel (Ni) & Major \\
\hline & Palladium $(\mathrm{Pd})$ & $3.6 \pm 0.1$ & $\operatorname{Tin}(\mathrm{Sn})$ & Minor \\
\hline & Lead tetroxide $\left(\mathrm{Pb}_{3} \mathrm{O}_{4}\right)$ & $0.3 \pm 0.1$ & Antimony (Sb) & Trace \\
\hline & & & Arsenic (As) & Trace \\
\hline & & & Bismuth (Bi) & Trace \\
\hline & & & Palladium (Pd) & Trace \\
\hline & & & Silver (Ag) & Trace \\
\hline \multirow[t]{3}{*}{ C } & Zinc $(\mathrm{Zn})$ & $97.9 \pm 0.2$ & Zinc $(\mathrm{Zn})$ & Main \\
\hline & Palladium (Pd) & $1.2 \pm 0.1$ & Palladium (Pd) & Minor \\
\hline & Herzenbergite $(\mathrm{SnS})$ & $0.9 \pm 0.2$ & & \\
\hline
\end{tabular}

Results of ND and NRCA are reported in table 2.

The mouthpiece and the body of the flute present different compositions. From ND spectra, region A is found to be composed of lead, lead tetroxide, tin(II) sulphate and zincite, while NRCA confirms that this zone contains mainly lead with a minor amount of zinc and traces of antimony, arsenic, bismuth, palladium and tin. Region $\mathrm{C}$ shows, in the diffraction 


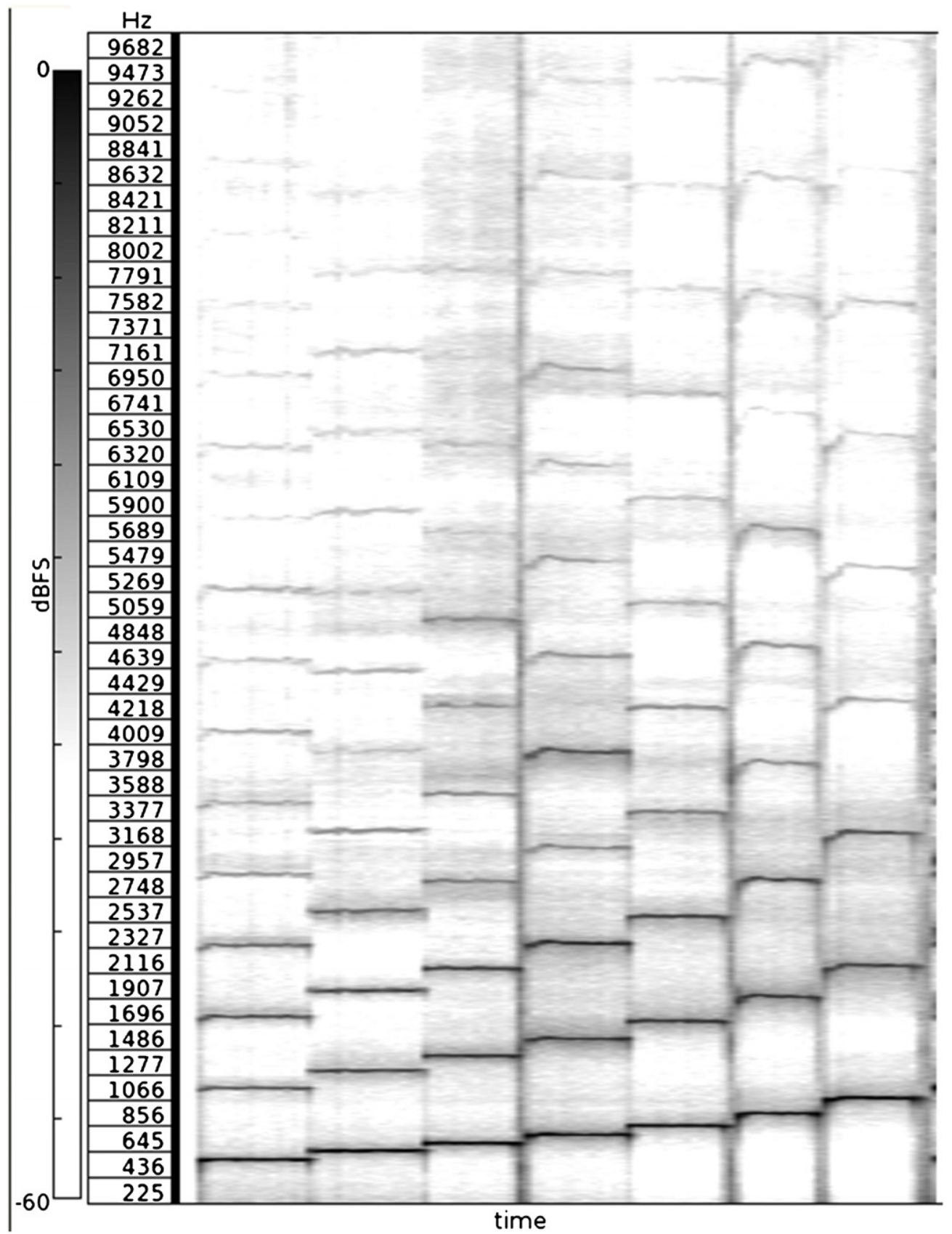

Figure 5. Spectrogram of the first scale normalized to $0 \mathrm{~dB}(\sim 33.7 \mathrm{~s})$. Spectrogram parameters: window shape: Hann window size 32768 with $50 \%$ overlap. Linear interpolation for $x$ and $y$ axes. Scale: $\mathrm{dBV}^{2}$.

patterns, the presence of zinc, palladium and herzenbergite ( $\mathrm{SnS})$, a corrosion product, while NRCA confirms the presence of zinc and a small amount of palladium.

The absorption resonances of antimony isotopes are very intense (for instance $E_{r} \sim 6.2 \mathrm{eV} ; \sigma \sim 1700 \mathrm{~b}$ ), and thus they are particularly evident in the NRCA spectrum, although the concentration of the metal in the alloy is not detected with other techniques. Some elements, like lead, sulphur and oxygen, are present as components in phases identified through ND in the sample, but they are not detected through NRCA because their resonances are at high energies (higher than $3 \times 10^{3} \mathrm{eV}$ ) or in the region between $10^{3}$ and $3 \times 10^{3} \mathrm{eV}$ (corresponding to a TOF in the range $28-50 \mu \mathrm{s}$ ) where the background is high, like the number of peaks.

The mouthpiece of the flute is found to be composed of lead coated by zinc and tin, which is generally used to protect the surface of lead objects from corrosion processes and visually give them a bright aspect. Antimony is generally present in lead as an impurity or added in low percentage to toughen the metal. Bismuth and arsenic are generally added to the tin to prevent the reconversion from $\beta$-tin (white tin) to $\alpha$-tin (gray tin, known as tin pest) [27].

In the welding region (B), the results of diffraction and NRCA measurements show the presence of new elements not detected in areas $\mathrm{A}$ and $\mathrm{C}$, i.e. copper, nickel and silver. As a 
matter of fact, a clear interpretation of the presence of silver is not completely certain at this stage. For soldering purposes silver, tin and lead melt at very different temperatures. It can be excluded that nickel, copper and silver are part of the welding because of the lower fusion temperature of lead, $345^{\circ} \mathrm{C}$, than that of nickel, copper and silver, even in the best eutectic configuration where it turns out to be $779.1{ }^{\circ} \mathrm{C}$ [28]. However, an indication of the origin of such elements comes from the NR plate of the same region (see figure 1), and of region $\mathrm{D}$ (partly superimposed on the former) that shows the presence, otherwise invisible, of a plate (called fipple plug) used to compress and direct the player's breath. Such a plate is thus most likely made of the previously mentioned elements. Silver and copper are clearly visible in the NRCA spectra while they are not in diffraction, thanks to the high resonance cross sections. Silver is one of the most favoured elements to be detected through neutron resonance absorption methods, down to some parts per million [29].

Audio and spectral analysis of the flute was performed. A series of ascending scales were performed on the instrument and recorded with a Zoom $\mathrm{H} 4$ digital recorder $(48 \mathrm{kHz}$ sampling rate, 24 bit resolution, uncompressed wav file). Amongst these, three were picked as the best representative performances on a qualitative basis. Sonograms are shown in figure 4. Audio and spectral analysis show that the flute is tuned in $\mathrm{D}$ with its base note being $\mathrm{D}_{4}=587.33 \mathrm{~Hz}$, and thus the instrument uses the modern A $440 \mathrm{~Hz}$ reference tuning. A quantitative spectrum of the scales was extracted from the recorded .wav file through the Sonic Visualizer software [30]. Observation of the spectrogram revealed that the instrument's temperament is poorly tuned. The $\mathrm{F}_{4}$ is about 45 musical cents ${ }^{9}$ lower than the expected $\mathrm{F \#}_{4}(739.99 \mathrm{~Hz})$. The $\mathrm{A}_{4}, \mathrm{~B}_{4}$ and $\mathrm{C}_{4}$ notes also exhibit pitches which are about 20 to 50 cents lower than the expected notes (respectively $\mathrm{A}_{4} 880 \mathrm{~Hz}, \mathrm{~B}_{4} 987.7 \mathrm{~Hz}$ and $\mathrm{C \#}_{4} 1108.7 \mathrm{~Hz}$ ). The D, E and $G$ notes seem to be more stable, although the $D$ and $F$ were slightly higher-pitched in two of the performed scales. Because of the $440 \mathrm{~Hz}$ reference tuning and the period when the instrument was constructed, it seems very unlikely that the flute maker intended to use some different temperament or tuning reference, and thus intonation issues should be considered a flaw. Performance of notes in the second register (above the base octave) proved problematic, with the actual impossibility of obtaining clean, stable notes-above $\mathrm{C \#}_{4}-$ through overblowing. From the point of view of timbre, the flute shows a spectrum (and tone quality) similar to that of modern flutes, with a rich overtone-harmonic content and strong presence of the 3rd and 4th harmonics which gives it a bright piercing sound. Indeed the spectrogram of the audionormalized to $0 \mathrm{~dB}$ as reported in figure 5-shows harmonic traces up to the 12th harmonic overtone.

It was suggested that tuning issues are connected to the mouthpiece which was recently re-soldered: in fact, no written documentation is available to say that the two fragments into which the instrument was reported are really coherent. The

\footnotetext{
9 The cent, in music, is a logarithmic unit of measure used for musical intervals. Twelve-tone equal temperament divides the octave into 12 semitones of 100 cents each
}

mouthpiece can have an impact on air-flow and thus the difficulty on this instrument of performing notes from the second register through overblowing. While there seems to be no scientific proof that the pipe material has an influence on the instrument's tone [31], experienced instrument makers state that different materials produce different tones: for this reason, a non-destructive investigation of the materials constituting the two fragments was especially valuable.

\section{Conclusions}

Integrated and simultaneous neutron analyses were performed on a small metallic duct flute from Accademia Nazionale di Santa Cecilia Musical Instruments Collection, providing unique information on its composition and manufacture, in a completely non-destructive manner. Indications on the elemental and phase compositions of the sample were obtained via neutron resonance capture analysis and neutron diffraction techniques, revealing an inhomogeneous composition of the flute. The mouthpiece of the flute was found to be mainly composed by lead, a material typically used for small organ pipes. The body of the instrument is mainly composed of zinc, generally used for larger organ pipes. The construction technique is that used for organ pipes and ancient wind instruments. The laminated metal sheet is covered with an electrochemical bath of palladium and rolled into shapes around molds and soldered together. The palladium covering was probably necessary to combat corrosion and oxidation of the zinc caused by the breath and fingers of the player. Our measurement suggest that the fipple plug of the instrument, located in its inner part, is composed of silver, copper and nickel. An additional advantage was that the simultaneity of the measurements resulted in a very low residual activation of the sample. This was achieved with the use of an integrated setup of neutron-based analytical methods at a single beamline.

The sound analysis revealed that the temperament of the instrument is poorly tuned with $\mathrm{A}_{4}, \mathrm{~B}_{4}$ and $\mathrm{C}_{4}$ notes exhibiting pitches about 20 to 50 cents lower than the expected notes. It was suggested that tuning issues are connected to the mouthpiece, which was re-soldered and is composed of a different material and manufacture. While the body could be clearly ascribed to French flute maker Charles Mathieu (19th century), there is no evidence that the mouthpiece is unequivocally part of the same instrument. The soldered mouthpiece could have an impact on air flow and thus the difficulty on this instrument of playing notes from the second register through overblowing. From the material analysis and the rough positioning of the holes, it can be likely concluded that the flute was intended for popular and amateur use.

A systematic experimental study on timbre produced by flutes (or pipes) with exactly the same construction characteristics but made of different materials would be valuable. In this respect also a synergic interplay among researchers from different fields, such as physicists, engineers, acousticians, musicians and manufacturers of metallic musical instruments, would be very interesting for a systematic investigation of these objects to find out common strategies and effective methodologies of integrated analysis to gain physical, historical, technical and artistic information. 


\section{Acknowledgments}

This work was supported within the CNR-CCLRC agreement no. 01/9001 concerning collaboration in scientific research at the spallation neutron source ISIS. The financial support of the Consiglio Nazionale delle Ricerche in this research is hereby acknowledged. We are grateful to Master Giovanni Tardino and Enrico Perelli Cippo for valuable discussions.

\section{References}

[1] Shull C G 1995 Early development of neutron scattering Rev. Mod. Phys. 67 753-7

[2] Squires G L 1996 Introduction to the Theory of Thermal Neutron Scattering 2nd edn (Mineola, NY: Dover)

[3] Postma H and Schillebeeckx P 2005 Non-destructive analysis of objects using neutron resonance capture $J$. Radioanal. Nucl. Chem. 265 297-302

[4] Postma H and Schillebeeckx P 2009 Neutron resonance capture and transmission analysis Encyclopedia of Analytical Chemistry (New York: Wiley) pp 1-22

[5] Lehmann E H, Vontobel P and Wiezel L 2001 Properties of the radiography facility NEUTRA at SINQ and its potential for use as European reference facility Nondestr. Test. Eval. 16 191-202

[6] Calzada E, Schillinger B and Grünauer F 2005 Construction and assembly of the neutron radiography and tomography facility ANTARES at FRM II Nucl. Instrum. Methods A 542 38-44

[7] Siano S, Bartoli L, Zoppi M, Kockelmann W, Daymond M, Dann J A, Garagnini M G and Miccio M 2003 Microstructural bronze characterisation by time of flight neutron diffraction Proc. Archaeometallurgy in Europe vol 2 pp 319-29

[8] Grazzi F, Bartoli L, Civita F and Zoppi M 2009 Ancient and historic steel in Japan, India and Europe, a non-invasive comparative study using thermal neutron diffraction Anal. Bioanal. Chem. 395 1961-8

[9] Festa G et al 2009 A nondestructive stratigraphic and radiographic neutron study of Lorenzo Ghiberti's reliefs from paradise and north doors of Florence baptistery J. Appl. Phys. 106074909

[10] Festa G, Senesi R, Alessandroni M, Andreani C, Vitali G, Porcinai S, Giusti A M, Materna T and Paradowska A 2011 Non-destructive neutron diffraction measurements of cavities, inhomogeneities, and residual strain in bronzes of Ghiberti's relief from the Gates of Paradise J. Appl. Phys. 109064908

[11] Cattaneo R, Trere C C, Mordeglia L, Gorini G, Cippo E P, Bartoli L, Kockelmann W and Scherillo A 2011 Integrated $\mathrm{x}$-ray and neutron-based analysis of bronze artefacts from the Ligurian settlement of Guardamonte-Monte Vallassa J. Anal. At. Spectrosc. 26 1024-9

[12] Manescu A, Fiori F, Giuliani A, Kardjilov N, Kasztovszky Z, Straumal B and Rustichelli F 2008 Non-destructive compositional analysis of historic organs reed pipes J. Phys.: Condens. Matter 20104250

[13] Grazzi F, Celli M, Siano S and Zoppi M 2007 Preliminary results of the Italian neutron experimental station INES at ISIS: archaeometric applications Nuovo Cimento C 3059

[14] Imberti S, Kockelmann W, Celli M, Grazzi F, Zoppi M and Botti A 2008 Neutron diffractometer INES for quantitative phase analysis of archaeological objects Meas. Sci. Technol. 19034003

[15] Windsor C G 1981 Pulsed Neutron Scattering (London: Taylor and Francis)

[16] Bedogni R, Esposito A, Andreani C, Senesi R, De Pascale M P, Picozza P, Pietropaolo A, Gorini G, Frost C D and Ansell S 2009 Nucl. Instrum. Methods A $\mathbf{6 1 2} 143$

[17] Pietropaolo A and Senesi R 2011 Electron volt neutron spectrometers Phys. Rep. 508 45-90

[18] Pietropaolo A, Festa G, Grazzi F, Barzagli E, Scherillo A and Schooneveld E M 2011 A multitask neutron beam line for spallation neutron sources Europhys. Lett. 9548007

[19] Grazzi F, Scherillo A and Zoppi M 2009 A neutron imaging device for sample alignment in a pulsed neutron scattering instrument Rev. Sci. Instrum. 80093704

[20] Hill R J and Howard C J 1987 Quantitative phase analysis from neutron powder diffraction data using the Rietveld method J. Appl. Cryst. 20 467-74

[21] Arletti R, Cartechini L, Rinaldi R, Giovannini S, Kockelmann W and Cardarelli A 2008 Texture analysis of bronze age axes by neutron diffraction Appl. Phys. A 90 9-14

[22] Copley J R D and Udovic T J 1993 Neutron time-of-flight spectroscopy J. Res. Natl Inst. Stand. Technol. 98 71-87

[23] Tardocchi M, Gorini G, Pietropaolo A, Andreani C, Senesi R, Rhodes N and Schooneveld E M 2004 YAP scintillators for resonant detection of epithermal neutrons at pulsed neutron sources Rev. Sci. Instrum. 75 4880-90

[24] Mughabghab S F, Divadeenam M and Holden N E 1981 Neutron Resonance Parameters and Thermal Cross Sections (New York: Academic)

[25] Larson A C and von Dreele R B 1986 GSAS: general structure analysis system Report LAUR 86-748 (Los Alamos, NM: Los Alamos Laboratory)

[26] Toby B H 2001 EXPGUI, a graphical user interface for GSAS J. Appl. Cryst. 34 210-3

[27] Puttlitz K J and Stalter K A (ed) 2004 Handbook of Lead-Free Solder Technology for Microelectronic Assemblies (New York: Marcel Dekker)

[28] Baker H (ed) 1992 ASM Handbook: Alloy Phase Diagrams vol 3 (Materials Park, OH: ASM International)

[29] Schooneveld E M et al 2009 A new position-sensitive transmission detector for epithermal neutron imaging J. Phys. D: Appl. Phys. 42152003

[30] Channam C and Queen Mary University London 2005-2012 Sonic Visualiser www.sonicvisualiser.org

[31] Backus J and Hundley T C 1966 Wall vibrations in flute organ pipes and their effect on tone J. Acoust. Soc. Am. 39 936-45 